\title{
Multifield Environmental Analysis and Hazards Prevention of Steeply Inclined Deep Coal Mining
}

\author{
Xingping Lai, ${ }^{1,2,3}$ Jingjing Dai $\left(\mathbb{D},{ }^{1}\right.$ Haidong $\mathrm{Xu}^{1}$ and Xingzhou Chen ${ }^{4}$ \\ ${ }^{1}$ College of Energy Science and Engineering, Xi'an University of Science and Technology, Xi'an, Shaanxi 710054, China \\ ${ }^{2}$ State Key Laboratory of Coal Resources in Western China, Xi'an University of Science and Technology, Xi'an, \\ Shaanxi 710054, China \\ ${ }^{3}$ Key Laboratory of Western Mine Exploration and Hazard Prevention, Ministry of Education, \\ Xi'an University of Science and Technology, Xi'an, Shaanxi 710054, China \\ ${ }^{4}$ College of Civil and Architecture Engineering, Xi'an University of Science and Technology, Xi'an, Shaanxi 710056, China
}

Correspondence should be addressed to Jingjing Dai; 18203078030@stu.xust.edu.cn

Received 25 October 2020; Accepted 8 May 2021; Published 25 May 2021

Academic Editor: Nimbalkar Sanjay

Copyright (c) 2021 Xingping Lai et al. This is an open access article distributed under the Creative Commons Attribution License, which permits unrestricted use, distribution, and reproduction in any medium, provided the original work is properly cited.

Due to the different in-situ stress level, mining stress state, and surrounding rock properties of steeply inclined deep coal mining, the mutation mechanism of underground engineering rock mass is complex. This paper studies the cause and control of mining disaster of steeply inclined deep coal resources in Wudong coal mine. The results show that the structural field is the key of multifield analysis, and particularly a large area of suspended roof is easy to expand energy and induce dynamic hazards. By means of borehole television- (BT-) transient electromagnetic (TEM) detection, it is found that there are hidden dangers of roof safety and suspected water hazards in Wudong coal mine, and the roof above the detection area ( $+575 \mathrm{~m}$ south roadway to $2250-2600 \mathrm{~m}$ ) is in a suspended state; there is a suspected water-rich area in the range of $2320-2340 \mathrm{~m}$ and $2390-2400 \mathrm{~m}$, and the lowest vertical height is $+613.8-+615.5 \mathrm{~m}$. Exploring and releasing the water in the aquifer effectively reduced the water pressure; in $+575 \mathrm{~m}$ south roadway, $+587 \mathrm{~m}$ measure roadway, and blasting chamber, the suspended roof blasting holes are constructed. Microseism- (MS-) TEM monitoring shows that the apparent resistivity fluctuates significantly, the microseismic energy and events have been significantly reduced, and it is maintained at a low level for two consecutive weeks, confirming the effectiveness of the stable release of the high-stress roof in the $+575 \mathrm{~m}$ near stope area; at the same time, the safeguard measures for long-term roof dynamic monitoring are constructed.

\section{Introduction}

Coal is the main basic energy and chemical raw material in China. Based on the total energy consumption, China's coal consumption demand is predicted. In 2025, China's energy consumption demand will be $5.5-5.6$ billion tons of standard coal, of which coal accounts for $50 \%-52 \%$. China's main energy structure will always be dominated by coal before 2050 [1]. At present, coal resources in the shallow part of the Earth are gradually exhausted, and the exploitation of resources is advancing to the deeper part of the Earth. In the 1980s, the coal mining depth of Poland, Germany, Britain, Japan, and France exceeded $1000 \mathrm{~m}$, and the mining depth of
47 coal mines in China is more than $1000 \mathrm{~m}$. In the future, deep mining will become common [2].

However, "deep" does not refer to the depth, but the mechanical state determined by in-situ stress level, mining stress state, and surrounding rock properties [3-5]. Deep excavation of coal and rock mass exists in the complex geological environment of high geostress, high ground temperature, high karst water pressure, blasting vibration, impact unloading, mining disturbance, and other complex geological environments. Under the strong dynamic phenomenon, the mechanical response of deep mining coal and rock mass is significantly different from that of shallow coal and rock mass [6-8] and presents the strength of "structure 
field-stress field-fracture field-seepage field" coupling characteristics $[9,10]$.

On the one hand, the frequency and intensity of dynamic disasters are increasing significantly. For example, largescale suspended roof collapse, mine water inrush, coal and gas outburst, rock burst, and other problems emerge endlessly, which greatly complicate the catastrophe mechanism of underground engineering rock mass [11-17]; on the other hand, the "black box" mechanical process under strong disturbance and strong time effect of deep resource mining increases the difficulty of disaster control.

Steeply inclined coal seams are affected by high hydrostatic pressure, strong engineering disturbances, and complex surrounding rock properties, which are typical characteristics of deep rock mass stress states. In complex multifield geological environment, large-scale impact instability of high stress energy storage rock mass under engineering disturbance will cause dynamic disaster [18].

Mine safety has been threatened continuously, which has become an urgent problem in China's coal industry. This paper takes Wudong coal mine as an example, and the engineering geological environment and multifield interaction system of steeply inclined deep rock mass are analyzed. Then BT-TEM detection is used to realize multifield visualization characterization of deep coal and rock mass. Based on this, we put forward the measures of stable release of high stress suspended roof in deep near stope area. At the same time, combined with the technology of water exploration and drainage, the dynamic disaster is controlled. In this paper, we use deep MS-TEM detection to evaluate the effect of roof dynamics and establish long-term monitoring measures for roof dynamics in Wudong coal mine.

\section{Multifield Environment in Deep and Steep Coal Seam}

The macro law is that the total amount of matter that fully accumulates and reaches a sufficiently large degree, derived from a large number of micro collective behaviors, and it is separated from the law of another level of the system's micro details [19]. We define the multifield environment of coal and rock mass with steep dip as the four-field coupling state of "structure field-stress field-fracture field-seepage field." The microscopic behaviors are the whole process of micro damage evolution, crack expansion, and failure mechanical behavior, which are accompanied by the change of rock internal structure and related physical and chemical field phenomena; the macroscopic performances are that the roof suddenly collapses and other strata structure instability induce strong destructive dynamic disasters such as water, fire, coal, and gas outburst.

The geological conditions of the steeply inclined coal seams in the Urumqi mining area in China are complex. Wudong coal mine is located in the north wing of Badaowan syncline, with a monocline structure inclined to the south, and the thickness of No. 43 coal seam and No. 45 coal seam in their mining area are $37.5 \mathrm{~m}$ and $47.8 \mathrm{~m}$, respectively, with a dip of $157^{\circ}$ and an average dip angle of $45^{\circ}$. Coal seam roof is hard and stable, under horizontal section caving mining, the large-scale roof of goaf is a potential hazard source, and with the main mining level entering the deep, the catastrophic development mechanism of underground engineering rock mass is largely complicated. Moreover, multifield coupling phenomenon in mining area shows more difficulty in disaster control. Figure 1 shows the geographical location and mining layout of Wudong coal mine.

Figure 2 shows geological conditions that belong to "solid-gas-liquid" phase system and change motion under many fields such as "geological body structure field-stress field-deformation field-seepage field-fracture field-gravity field.”

Figure 3 is the multifield evolution process under engineering geology condition of Wudong coal mine, dynamic variation during incubation process, and structural field analysis foundation; water pressure is the motive force of fracture expansion, crack increase is caused by fracture field increase, and seepage field crack center gradually expands stress field and gradually differentiates high stress and low stress zone, finally forming low stress high permeability zone in vertical direction of main fissure. The multifield is interrelated and transits from microstate to macrostate, among which geological body structure field provides docking channel for multifield coupling.

\section{Disaster Detection and Prevention Measures}

In view of the multifield complex environment of deep mining coal and rock mass in Wudong coal mine, mastering the information of structural field is the key to control the stability of multifield environment. Therefore, the visualization information of deep ground exploration is obtained by joint monitoring method to guide the formulation of dynamic disaster precontrol measures.

3.1. BT-TEM Detects the Source of Hazards. There is a practical difficulty in the visualization of multifield environment of deep coal and rock mass under mining conditions. It is difficult to directly observe the mechanical behavior and internal physical process under engineering disturbance, which is a "black box" process [20]. According to the characteristics of electric, magnetic, and physical properties of goaf, borehole TV (BT) and transient electromagnetic method (TEM) are used to retrieve the spatial distribution characteristics of potential disasters in deep ground, such as type, scale, and depth; at the same time, the multifield evolution and mechanical behavior of deep coal and rock mass are analyzed.

3.1.1. Detection Principle. As shown in Figure 4(a), the geological structure and rock layer state parameters in the hole can be identified by scanning the shape and color of the borehole image, which can assist in judging the occurrence, lithologic distribution, structural development, and water and gas production of rock strata [21].

Transient electromagnetic method (TEM) is also called time domain electromagnetic method, which first creates the 


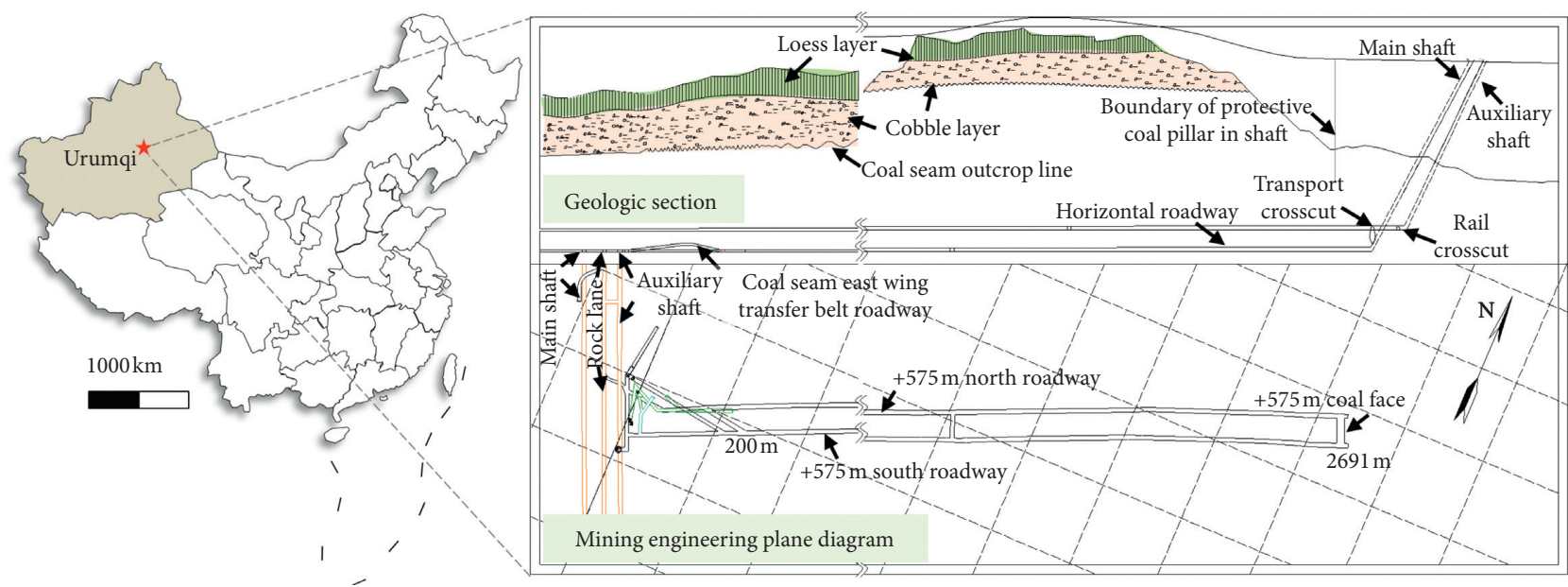

Figure 1: Geographical location and mining layout of Wudong coal mine.

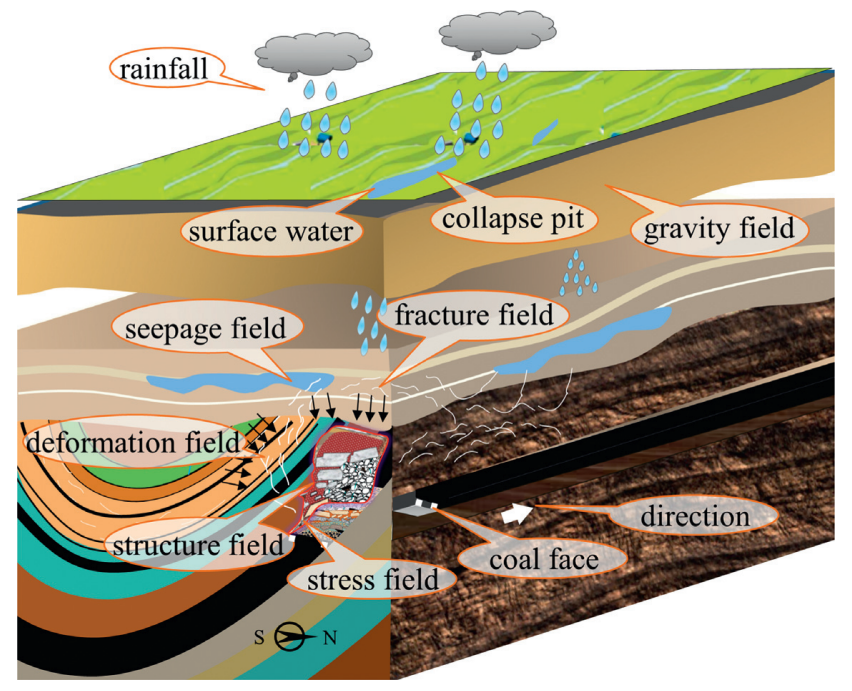

FIGURE 2: Schematic diagram of engineering geological multifield action of steeply inclined coal seam.

main magnetic field coil and then interrupts it suddenly. According to Faraday law of electromagnetic induction, electric conductor produces secondary induced currents on ground or coal mine, because the attenuation law of secondary magnetic field is related to the conductivity of underground geological body; the better the conductivity is, the slower the attenuation rate is [22].

This method has advantages of good directivity, large depth of detection, abundant information, and small investment in rock damage exploration of stope, which is a new idea for detecting surrounding rock damage in stope. Due to the difference of water conductivity, on the one hand, apparent resistivity values of different strata above goaf can be obtained from electrical data analysis; on the other hand, the apparent resistivity of fractured coal rock mass is greater than that of intact coal rock mass and water, while that of intact coal rock mass is greater than that of water (apparent resistivity: fractured coal rock mass $>$ intact coal rock mass $>$ water apparent resistivity). Therefore, through TEM detection results coal rock fragmentation zone and water zone can be identified and finally the influence range of coal rock fragmentation zone and water zone is determined, and principle is shown in Figure 4(b).

Calculation formula of apparent resistivity of coal mine full space transient electromagnetic method is [23]

$$
\begin{aligned}
\rho= & C \times\left(\frac{\mu_{0}}{4 \pi t}\right) \times\left(\frac{2 \mu_{0} S N^{2 / 3}}{5 t(V / I)}\right)=C \times 6.32 \times 10^{12} \\
& \times(S \times N)^{2 / 3} \times(V / I)^{2 / 3} \times t^{5 / 3},
\end{aligned}
$$

where $C$ is the full space response coefficient, $\mu$ is the permeability, which can be approximately taken as the vacuum permeability, $S$ is the coil area of the receiving loop, $n$ is the coil turns, $t$ is the attenuation time of the secondary magnetic field, and $V / I$ is the normalized secondary magnetic field potential value. follows:

Through time depth conversion, the equation is as

$$
h_{s}=\sqrt{\frac{\rho\left(t_{i}\right) \times t_{i}}{2 \mu_{0}}}
$$

In formula (2), $t_{i}$ is the time window value of the corresponding instrument at a certain time; $\rho\left(t_{i}\right)$ the apparent resistivity of the corresponding instrument can be obtained by $(1) ; \mu_{0}$ is the vacuum permeability $(4 \pi \times 10-7 \mathrm{H} / \mathrm{M})$ and $h_{s}$ is the depth.

3.1.2. Detection Equipment and Scheme. In order to detect the geological information of potential disaster sources, realize multifield visualization of engineering geology, and guide the formulation of field precontrol measures, the BTTEM detection scheme and equipment are shown in Figure 5.

(1) Observation of Strata Movement by BT. There exist different degrees of collapse pit and crack phenomenon during mining process of $+575 \mathrm{~m}$ coal seam while collapse 


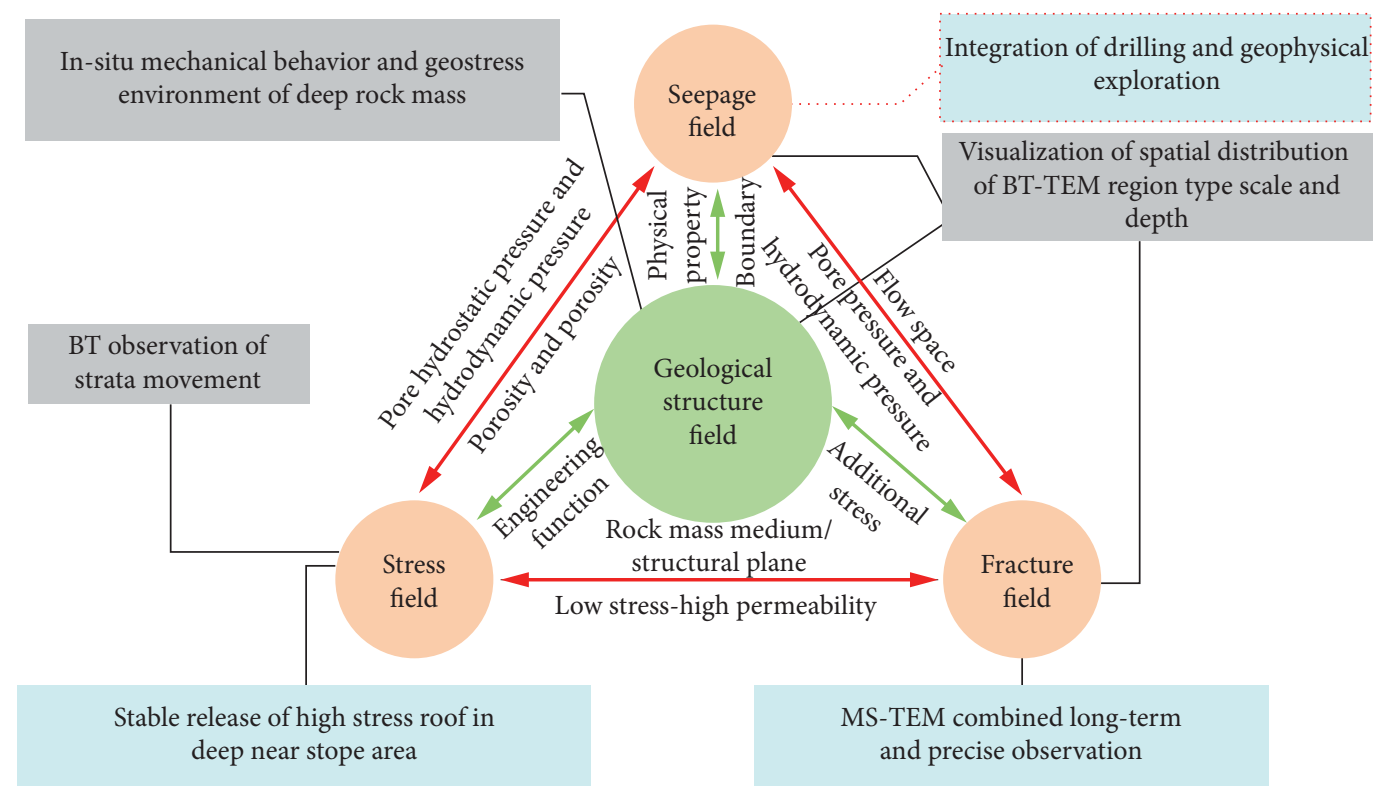

FIGURE 3: Multifield coupling relationship of coal and rock mass in steeply inclined coal seam.

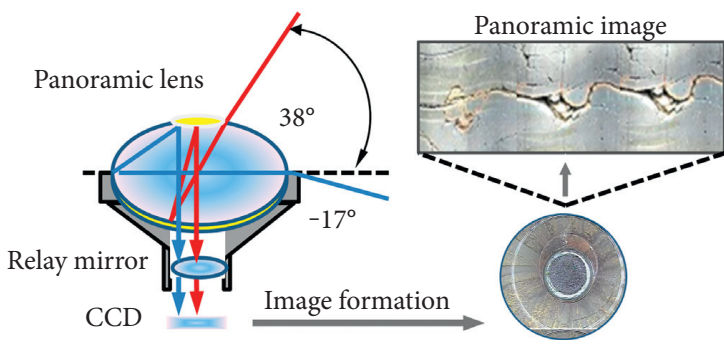

(a)

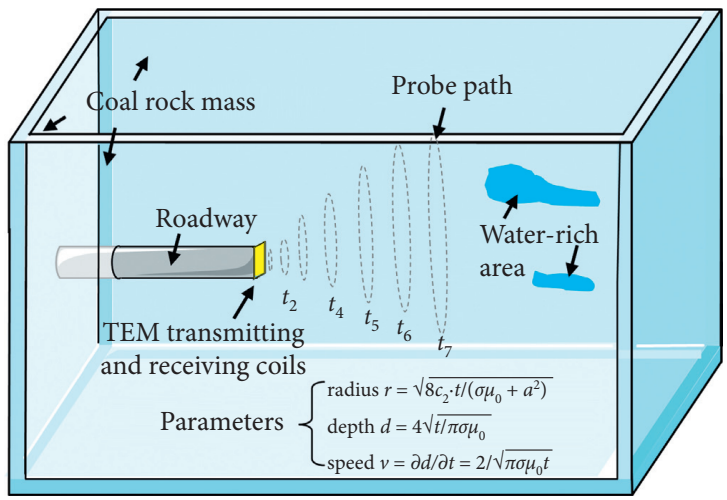

(b)

FIgUre 4: Principle of BT-TEM detection equipment: (a) borehole television principle; (b) mine transient electromagnetic detection principle.

pit has hysteresis and discontinuous characteristics, and roof safety hidden danger exists in coal seam area. In order to explore the occurrence of roof in goaf and ensure the safety of mine production, observation holes of strata movement are constructed on the corresponding surface of the goaf side, and the occurrence of overlying strata in goaf is detected by drilling, and detection scheme of strata movement is shown in Figure 6.

As shown in Figure 6(a), eleven strata moving observation holes are designed on corresponding surface of goaf side with diameter $100 \mathrm{~mm}$ and design length 130-210 m. Drilling holes are located within $20-80 \mathrm{~m}$ behind working face, the parameters of each borehole are shown in Figure 6(b), and the solid section of the probe hole is shown in Figure 6(c).
(2) Detection of Water-Rich Area by TEM. The mine transient electromagnetic method exploration device type uses the overlapping loop combination device; the side length is $1.5 \mathrm{~m}$ excitation and receiving square coil, the number of exciting coil turns is 4 , the number of receiving coil turns is 40 , power supply current is $60 \mathrm{~A}$, power supply pulse width is $10 \mathrm{~ms}$, and the sampling rate is $16 \mu \mathrm{s}$. Each measuring point adopts at least 30 times superposition to improve the signalto-noise ratio, which ensures the reliability of the original data.

As shown in Figure $7(\mathrm{a})$, each detection line in south roadway stops from $2608-2250 \mathrm{~m}$, probe angle are $45^{\circ}, 60^{\circ}$, and $90^{\circ}$ as shown in Figure 7 (c) (considering surface borehole survey and mine hydrogeological in-formation, three lines can cover water-rich area), and two measuring 


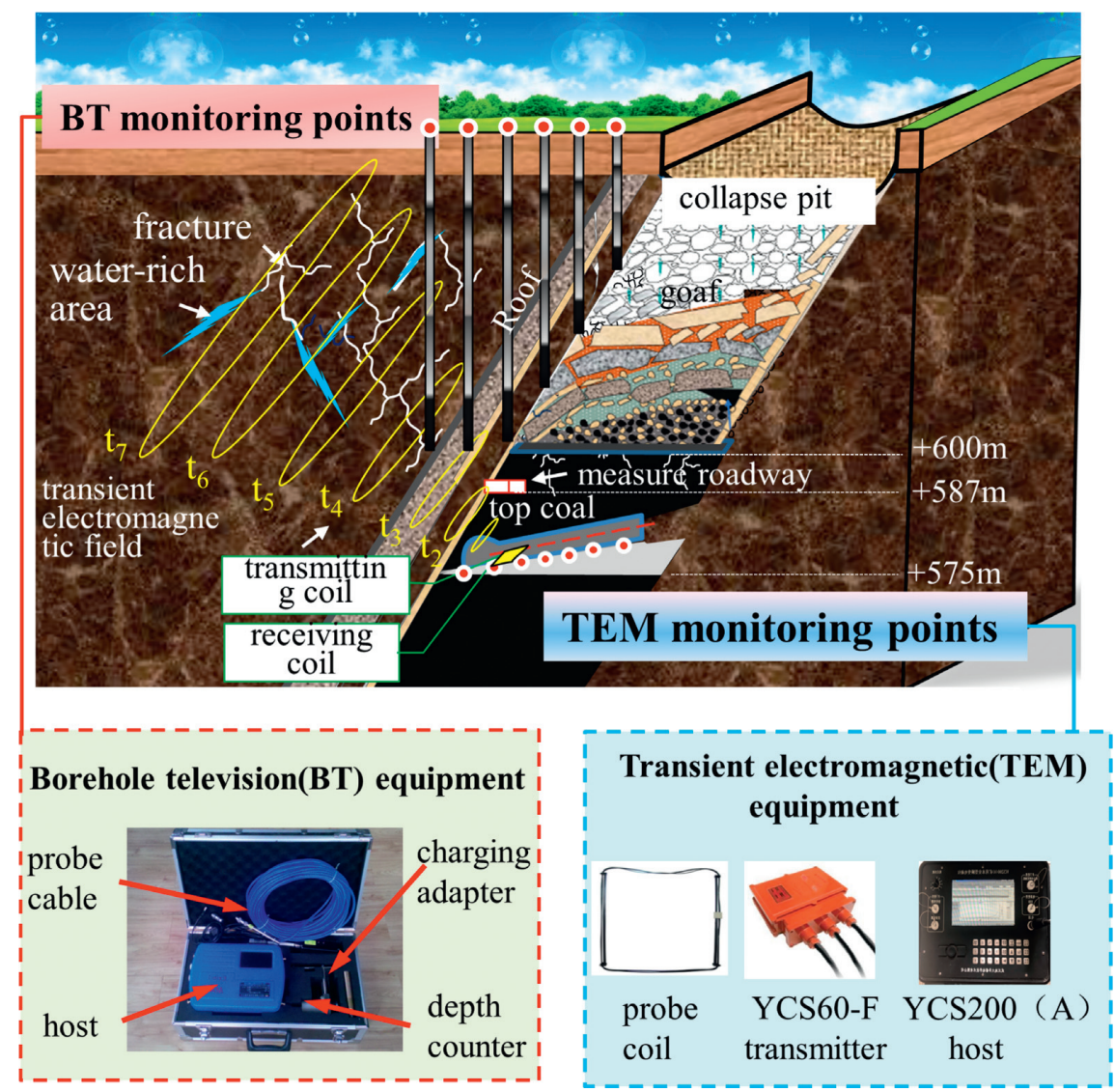

FIGURE 5: BT-TEM detection area and equipment.

lines are arranged along the $+587 \mathrm{~m}$ blasting measure roadway to detect the top $\left(90^{\circ}\right)$ and south side $\left(45^{\circ}\right)$ of the roadway. Each measuring line from $2400-2340 \mathrm{~m}$ and the detection interval is $20 \mathrm{~m}$.

\subsubsection{Disaster Source Visualization}

(1) BT Monitoring of Rock Fracture Evolution. Coal and rock mass changes from internal mesofracture to external macroscopic deformation and collapse under engineering disturbance. As shown in Figure 8(a), separation points, breaking points, and complete rock strata critical points are interpolated, respectively, into three regions: small range approximate arch shape fragmentation zone, rectangular suspended rock stratum, and trapezoid shape high stress concentrated intact hard rock zone.

Figure $8(\mathrm{~b})$ is the distribution of fracture and deformation under mining disturbance; it can be seen that, during mining process, 2\# and 7\# fracture deformation reach $0.1 \mathrm{~m}$ in fracture zone I, 3\# and 4 \# borehole deformation are smaller in fracture zone, and 5\# of area is not too large deformation. From structural perspective, bearing structure of goaf is "arch-beam" overburden structure; from mechanics development mechanism, the suspended rock beams in region III are divided into three zones: fracture initiation zone, separation zone, and compression zone; from roof deformation characteristics, maximum deformation position is along the middle direction of roof tilt direction.

The roof failure of goaf is found to be insufficient, zone is the force source of additional external force and energy accumulation, and rock stratum in zone is complete. Compared with shallow strata, depth stress environment and rock mechanics properties change energy aggregation and high intensity burst release process will be more obvious than shallow strata. Under high geostress and strong engineering disturbance, regions II and III can easily impact instability.

To sum up, we can prevent and control the dynamic disasters of Wudong coal mine from two aspects: (1) control the energy input by weakening the additional external force, for example, optimizing the coal drawing process and controlling the top coal caving ability can fully improve the resource recovery rate, reduce the residual triangular coal in the upper level, and avoid the formation of masonry beam structure along the inclination of the roof in the working face, which will affect the stable release of the roof; (2) by controlling roof span to control energy input area, the dynamic stability of rock beam is controlled by roof weakening, so as to achieve the purpose of stable release of deep and large hanging roof stress.

(2) TEM Detection of Water Source Information. After collecting data underground, the induced voltage is converted 


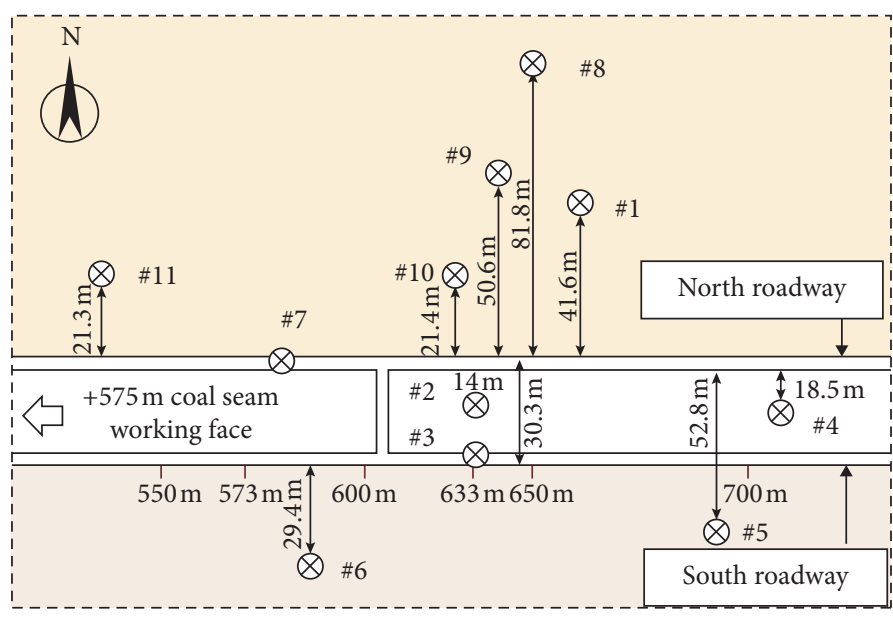

(a)

\begin{tabular}{lcc}
\hline Number & Strike $(\mathrm{m})$ & Length $(\mathrm{m})$ \\
\hline $1 \#$ & 650.0 & 130.4 \\
$2 \#$ & 632.9 & 182.3 \\
$3 \#$ & 632.9 & 197.4 \\
$4 \#$ & 714.0 & 186.9 \\
$5 \#$ & 696.8 & 209.8 \\
$6 \#$ & 589.0 & 209.8 \\
$7 \#$ & 581.3 & 173.7 \\
$8 \#$ & 647.2 & 90.80 \\
$9 \#$ & 638.8 & 121.2 \\
$10 \#$ & 626.9 & 149.9 \\
$11 \#$ & 533.3 & 149.9 \\
\hline
\end{tabular}

(b)

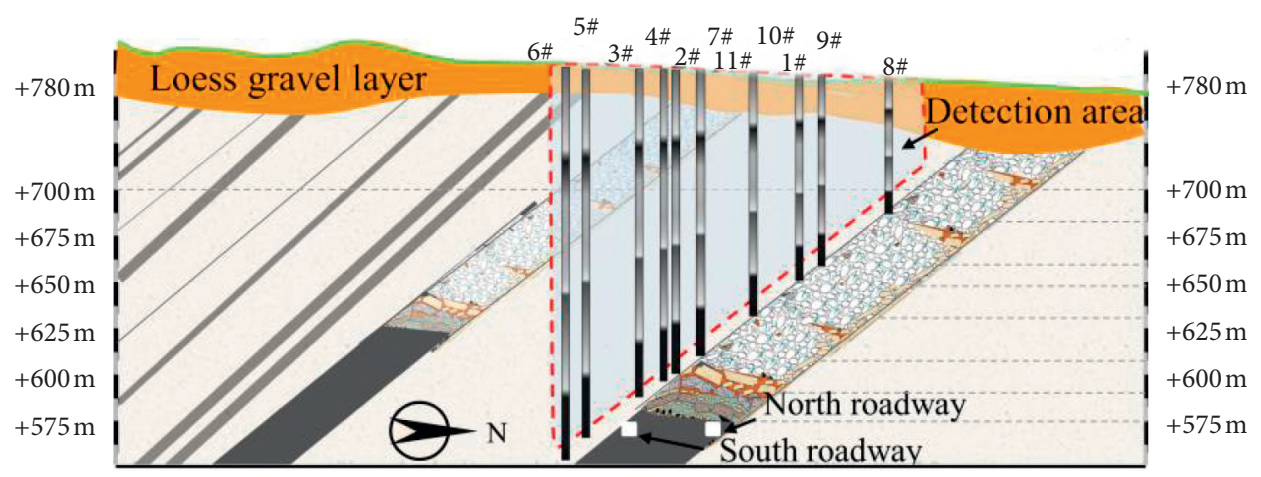

(c)

FiguRE 6: Detection scheme of strata movement: (a) detection hole scheme plane, (b) detection hole parameters, and (c) detection hole scheme section.

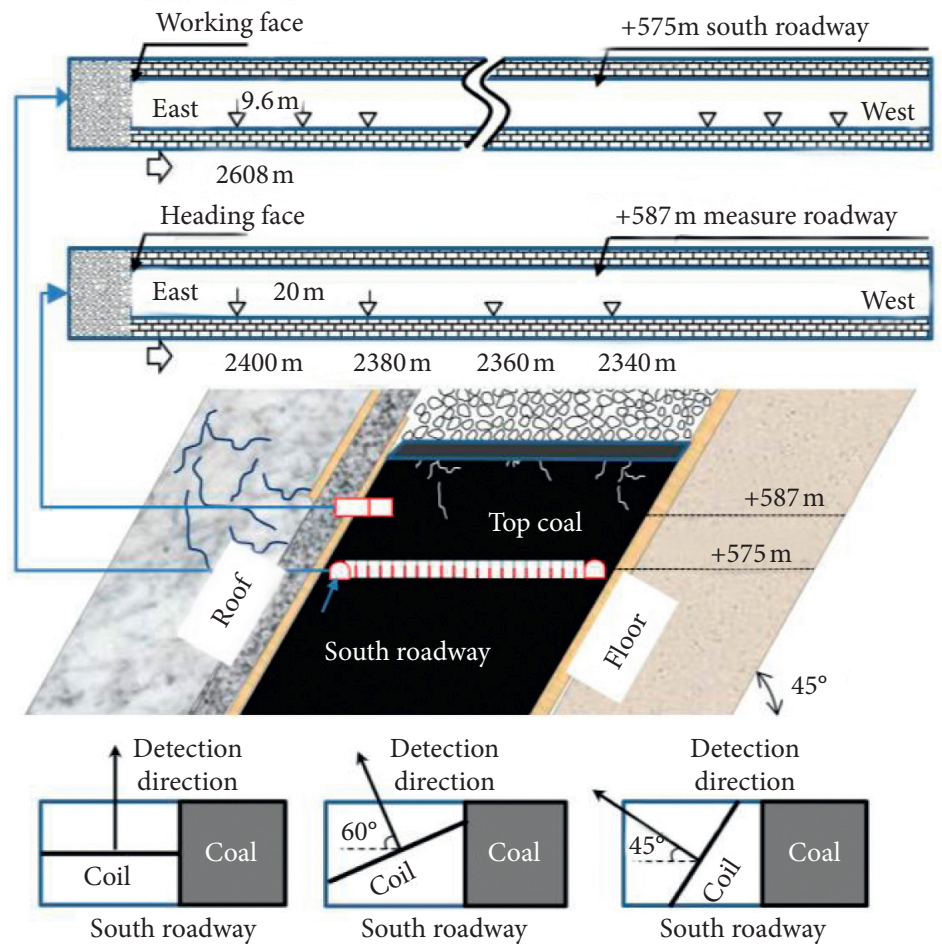

(a)

FIGURE 7: TEM monitoring scheme: (a) location of measuring points; (b) construction site; (c) angle of detection. 


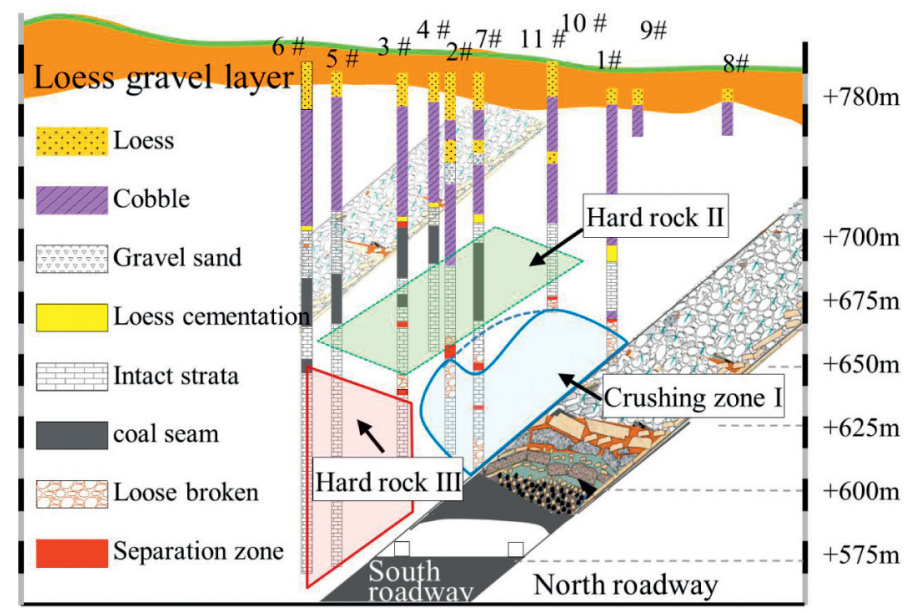

(a)

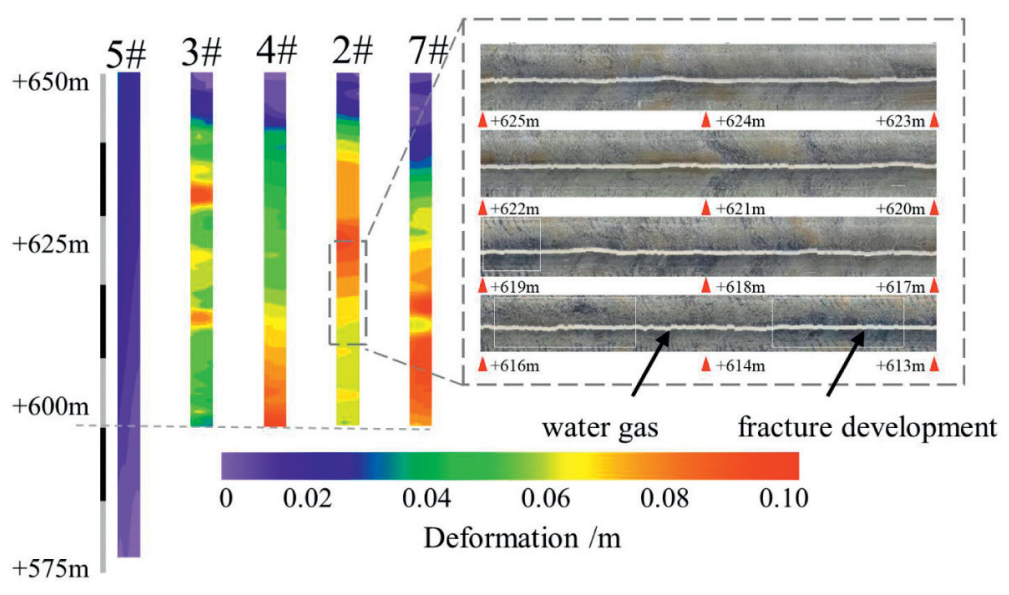

(b)

FIGURE 8: Fracture distribution and evolution diagram of coal and rock mass: (a) overburden structure visualization; (b) fracture evolution of coal and rock mass.

into apparent resistivity and time is converted into depth. Figure 9 shows the section of apparent resistivity of south roadway and measure roadway. The horizontal coordinates represent the measurement points in the roadway, and the vertical coordinates represent detection depth.

It can be seen from Figure 9 that the apparent resistivity of rock body in most detection areas is uniform and stable, which indicates that the roof strata is relatively complete, which indirectly verifies the BT detection results. However, there are two low resistivity anomaly areas in the south roadway strike of 2320-2340 $\mathrm{m}$ and 2390-2400 $\mathrm{m}$, which are obviously lower than other areas ((1) and (2)).

There is also a low resistivity area in the $2320-2345 \mathrm{~m}$ (winch chamber) of the measure roadway. Based on the analysis of geological data, it is speculated that the two low resistivity abnormal areas are suspected to be rich in water, while the lowest vertical height of area (2) is $+613.8-+615.5 \mathrm{~m}$; if it is not drained and the water pressure is not reduced in advance, it can be considered that the structural field damage leads to multifield environmental instability and induces dynamic disasters.

\subsection{Disaster Prevention Measures}

3.2.1. Water Exploration and Drainage. The related water disasters caused by deep mining activities are becoming more and more serious. Surface water, aquifer, fissure water, goaf water, and karst cave water are polluted, which lead to water related hazards; it is important to find water sources, water flow channels, and the interference of mining activities on aquifer.

Geophysical exploration means can carry out large-scale advanced and rapid detection of the whole mining face with small investment, and drilling method is intuitive and simple. Therefore, the integrated exploration of water exploration and drainage scheme is formulated. Firstly, BTTEM technology is used to determine the location of aquifer and some main fracture areas (the winch chamber strikes $2325.2-2342.6 \mathrm{~m}$ ), and there is a small range of separation at 613.8-615.5 $\mathrm{m}$. In addition, multiple boreholes (1\#, 2\#, 3\#, and 4\#) are applied in the underground measure roadway to effectively drain the static reserves of the aquifer and reduce its water pressure as much as possible. Figure 10 shows the 


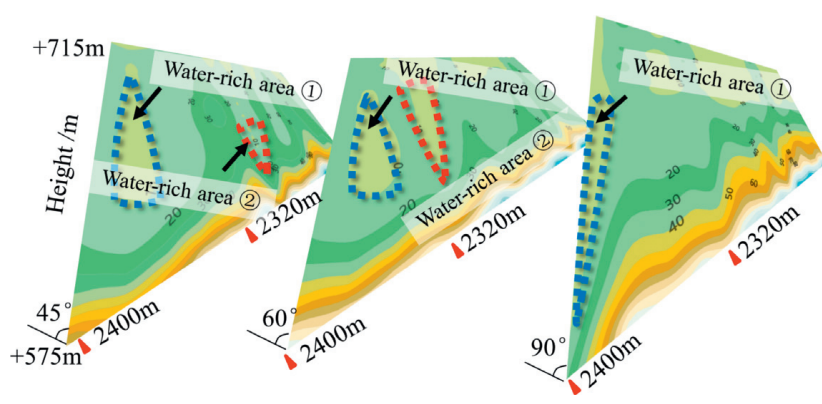

(a)
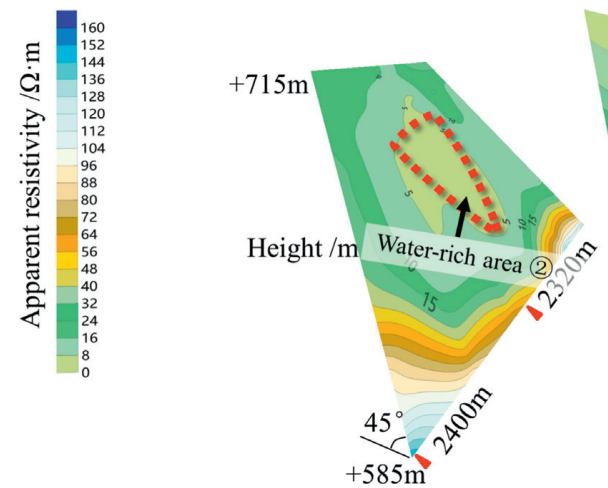

(b)

FIGURE 9: Visualization of water rich area detection: (a) south roadway, (b) measure roadway.

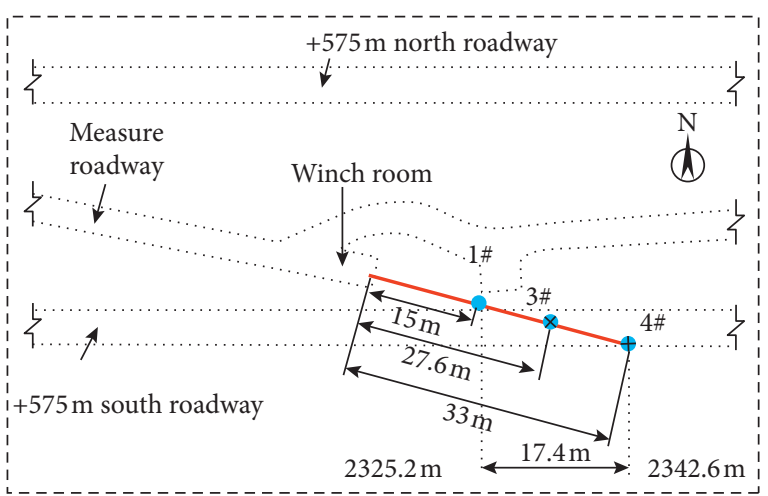

(a)

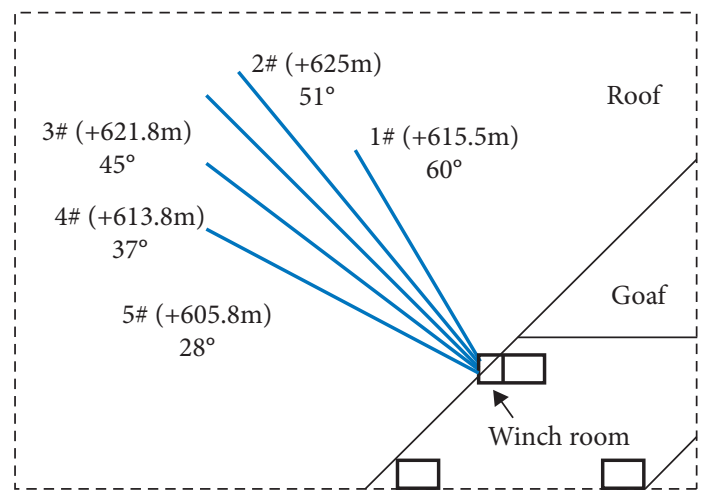

(b)

FIgURE 10: Layout of water outlet drilling in winch chamber. (a) plan; (b) section.

layout of water outlet drilling in winch chamber, and Table 1 shows the results of drilling water.

\subsubsection{Precracking of Large Area Suspended Roof. The blasting} holes of roof are constructed in $+575 \mathrm{~m}$ south roadway, + $587 \mathrm{~m}$ blasting chamber, and measure roadway. Figure 11(a) shows the stereoscopic diagram of blast holes layout.

The specific construction is as follows: (1) each row of $+575 \mathrm{~m}$ south roadway is arranged with two roof blasting holes with row spacing of $10000 \mathrm{~mm}$, as shown in Figure 11(b); (2) blasting chamber is $4500 \mathrm{~mm}$ wide, $3000 \mathrm{~mm}$ high, and $5000 \mathrm{~mm}$ deep, and the construction quality meets the basic requirements of coal mine safety production standardization. Along the coal seam strike, blasting holes are constructed to the east, west, and up, respectively, with a diameter of $113 \mathrm{~mm}$, and a total of 9 roof blast holes are constructed. The construction parameters of blasting chamber and blast hole are shown in Figure 11(c); (3) three roof blasting holes are arranged in each row in the measure roadway, and the row spacing of blasting holes is $10000 \mathrm{~mm}$, as shown in Figure 11(d); (4) using emulsion matrix explosive, the blasting holes are sealed with loess, and the sealing length is not less than $1 / 3$ of the blast hole length; (5) firstly, four holes in the east of the chamber and the holes in the measure roadway to the east of the chamber are blasted, and then the holes in the top, west, and west of the chamber are blasted; (6) the blasting sequence of the roof in the south roadway of the $+575 \mathrm{~m}$ is from east to west.

\section{Engineering Evaluation}

Rock mass fracture and rock sliding will produce obvious acoustic signals. Therefore, in view of multifield environment of deep mining coal and rock mass in steeply inclined coal seam, the establishment of MS-TEM joint monitoring and evaluation may bring new progress to dynamic disaster prediction in deep coal resource mining. In addition, the stability of deep roof release can be judged by combining with the observation hole technology of mining induced fracture, and the multifield change information can be obtained.

When the roof above the goaf is not cracked, the electrical properties of the same rock layer change uniformly due to the integrity of the overlying rock structure. When the 
TABLE 1: Effluent from multiple boreholes.

\begin{tabular}{lcccccc}
\hline Position & Number & Angle $\left(^{\circ}\right)$ & Diameter $(\mathrm{mm})$ & Length $(\mathrm{m})$ & Horizontal elevation $(\mathrm{m})$ & Water column $(\mathrm{mm})$ \\
\hline \multirow{3}{*}{ Winch chamber $2312 \mathrm{~m}$} & $1 \#$ & 60 & 113 & 30 & +615.5 & Full hole \\
& $3 \#$ & 45 & 113 & 39 & +621.4 & 19 \\
& $4 \#$ & 37 & 113 & 40 & +613.8 & 38 \\
\hline
\end{tabular}

Note: after $4 \#$ holes water drains out, $1 \#$ hole and 2\# hole no longer have water.
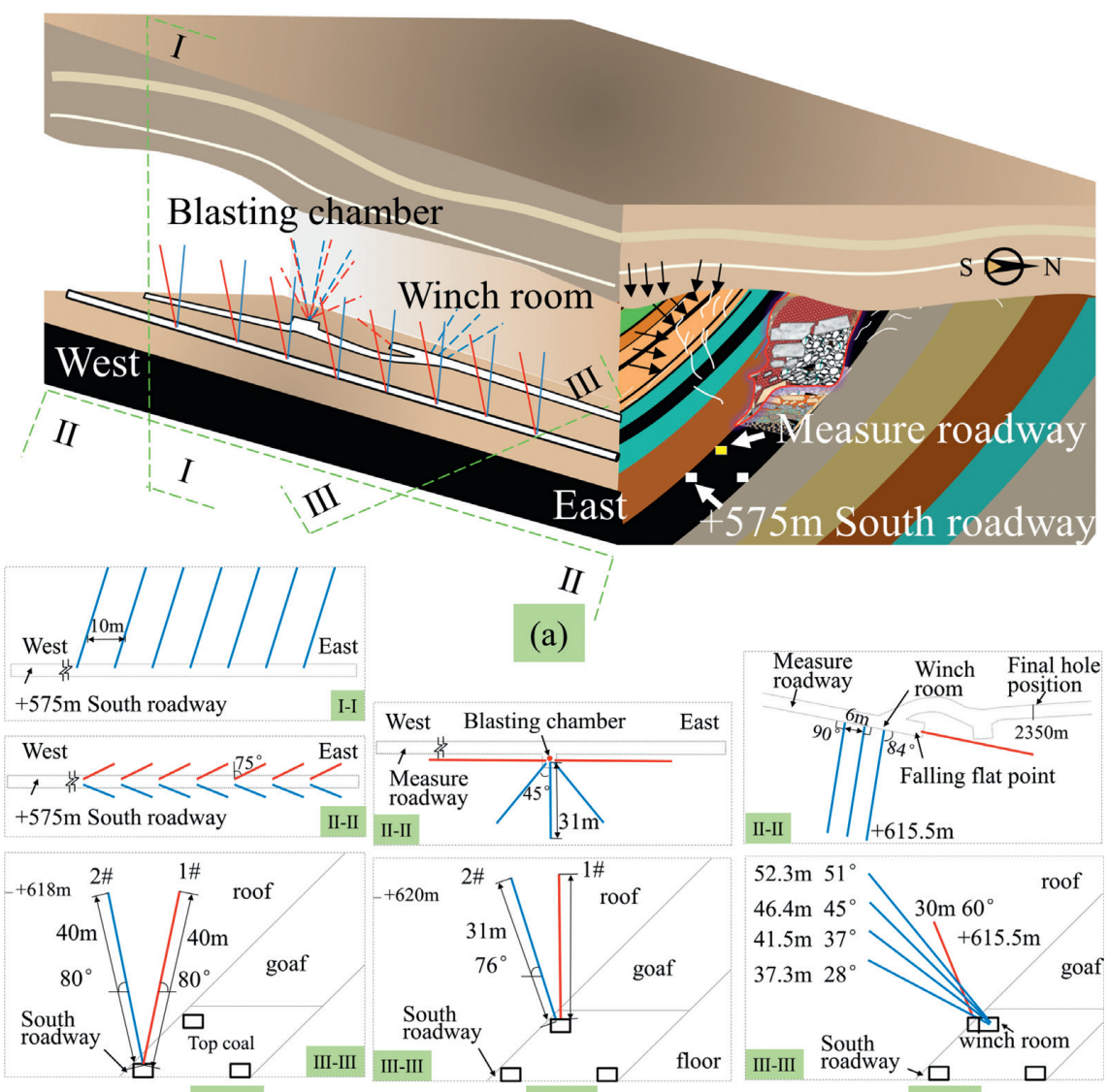

(b)

(c)

(d)

FIGURE 11: Blast hole layout of precracking suspended roof. (a) Stereogram of blasthole arrangement; (b) layout of blasting holes in south roadway; (c) layout of blasting holes in blasting chamber; (d) layout of blasting holes in winch room.

high stress roof is released smoothly, there are cracks and separation space in the affected area, which provides the flow space for various filling bodies and shows the electrical characteristics different from the surrounding rock. The apparent resistivity of the fracture development area is higher than that of the intact surrounding rock when the water is not filled. When there is a water-rich area nearby and the fracture development area is full of water, the apparent resistivity of the area is relatively low.

The area where the apparent resistivity decreases greatly in Figure 12(a) indicates that the water content is high. Due to the participation of pressure water and the destruction of rock mass structure, the distribution state of internal current field changes, thus reducing the apparent resistivity. Fracture propagation is the external manifestation of multifield coupling effect, and its size, distribution, and change reflect the coupling degree of each action field. In fact, this is also the influence area of roof precracking, such as $\mathrm{B}_{1}, \mathrm{~B}_{2}$, and $\mathrm{B}_{3}$, because there is a water-rich area (1); after blasting, cracks provide strain space for stress action, in which the black solid line arrow indicates the fracture expansion, and the blue dotted arrow indicates the seepage direction.

Area $A_{1}$ is the original water-rich area. After fracturing, the geological structure field is destroyed, the pressure water flows to fracture field $B_{1}$ under the action of gravity field, so separation cavity is formed, showing the phenomenon of increased resistivity. The increase of resistivity in areas $A_{2}$ and $A_{3}$ is the result of effective roof fracturing. Because of effective drainage before fracturing in area C, there is no low resistance anomaly phenomenon, which also verifies the feasibility of water exploration and drainage scheme. 


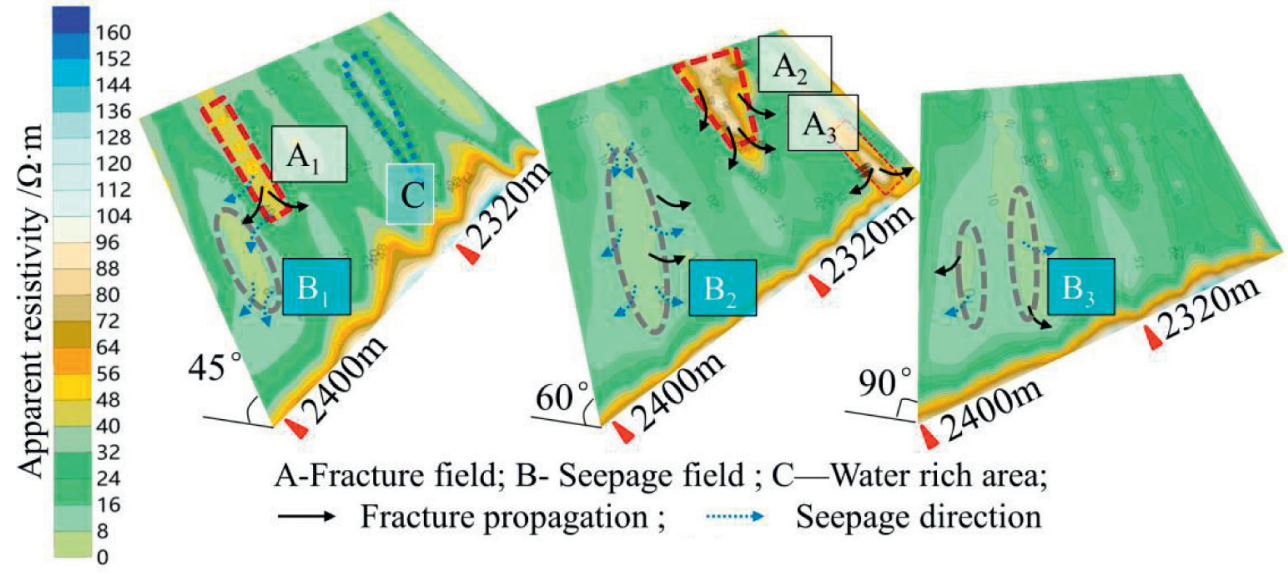

(a)
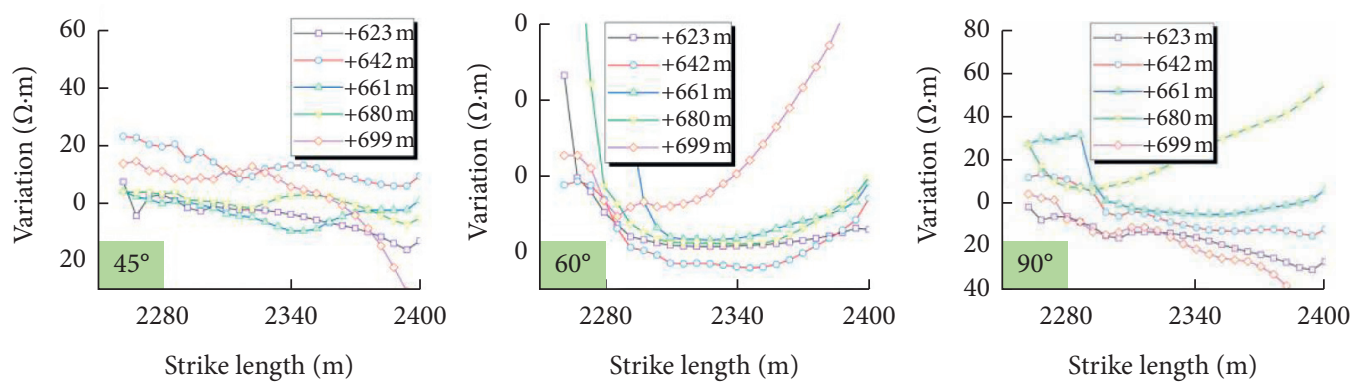

(b)

FIGURE 12: Visualization of effect after high stress roof cracking: (a) multifield spatial evolution diagram; (b) variation diagram of apparent resistivity of survey line.

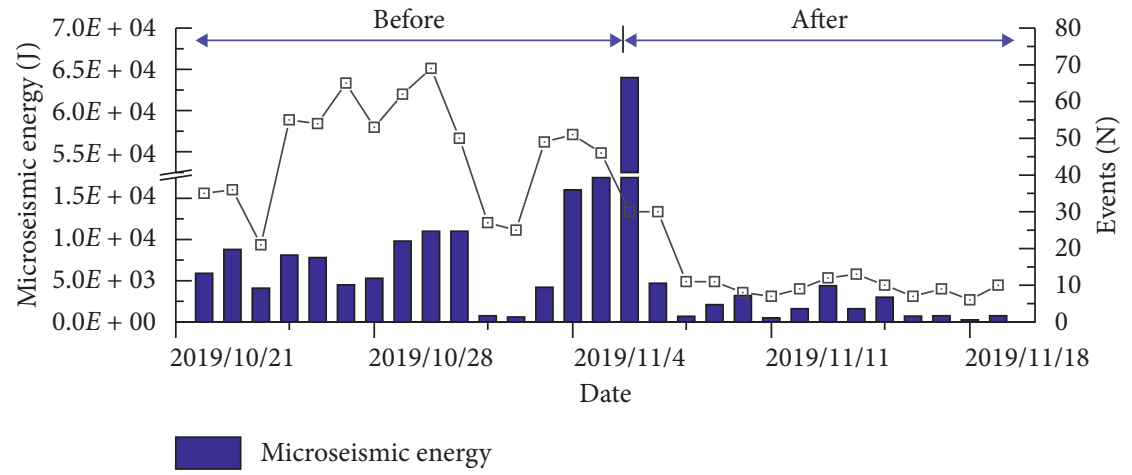

FIGURE 13: Microseismic energy and events distribution of roof weakening.

According to Figure 12(a), five typical survey lines $(+699 \mathrm{~m},+680 \mathrm{~m},+661 \mathrm{~m},+642 \mathrm{~m}$, and $+623 \mathrm{~m})$ are selected to extract the corresponding apparent resistivity of each line. Figure 12(b) shows the variation law of apparent resistivity of five survey lines after blasting; it can be seen that each survey line fluctuates greatly after fracturing, which indicates that the roof precracking measures effectively affect the structure field state. The increase of this value is due to the expansion of the fracture field caused by roof cracking, while part of the reduction area is mainly along the strike of $2400 \mathrm{~m}$. As the previous analysis, the fracture field in $B_{1}, B_{2}$, and $\mathrm{B}_{3}$ areas after fracturing expand to provide flow space for the upper aquifer.

It can be considered that the underground seepage field changes with the geological structure field, the change of fluid pressure in the fracture field changes the width and length of the fracture, and the changes of the far-field stress and the fracture induced stress also restrict the fracture width and fluid pressure in the fracture. Combined with the phenomenon of the apparent resistivity increase in $A_{1}, A_{2}$, and $A_{3}$ areas, it can be concluded that the effective fracture area of the roof increases under the multifield coupling 


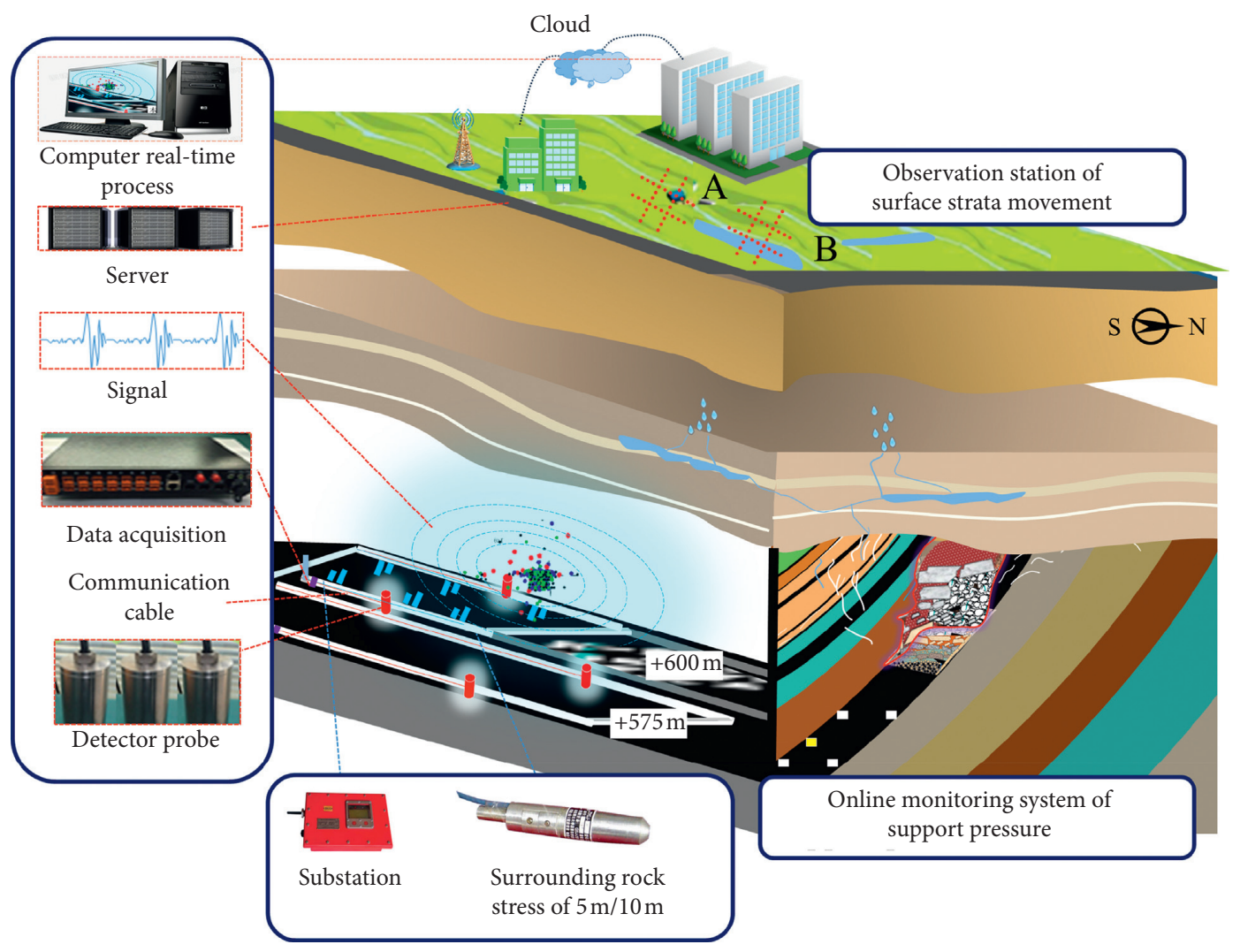

FIGURE 14: Long-term monitoring of roof dynamic by microseismic system.

effect. In addition, through the observation hole of ground strata movement, it is found that some of the existing boreholes are broken in a large range and the probe is difficult to lower, which verifies the reliability of the analysis.

Figure 13 shows the distribution of microseismic events and energy. On November 4, 2019, Wudong coal mine carried out blasting measures on the roof of $+575 \mathrm{~m}$ coal seam. At this time, the microseismic events and energy of the working face reached the maximum value. After November 4 , the value decreased significantly and remained at a low level in the past two weeks; this shows that the high stress roof is released smoothly and does not cause multifield environmental instability, and it also proves that the stable release measures of suspended roof are effective.

In order to detect the collapse of the suspended roof, borehole TV monitoring is carried out on the roof regularly; at the same time, online monitoring systems of microearthquake (ESG), roof dynamic monitoring (KJ216), and support pressure (KJ327) are arranged at the working face, and observation stations are set up on the surface to monitor the ground collapse. Through the real-time comprehensive analysis of monitoring data, the roof activity information can be mastered in time to guide the production practice, and the monitoring system is shown in Figure 14.

\section{Conclusion}

(1) As Wudong coal mine enters the deep coal resource mining, compared with the shallow coal mine, the multifield environment is more complex; it is necessary to take measures to control the area and size of roof energy input (optimizing mining technology, controlling caving ability, and limiting roof span), so as to avoid dynamic disaster caused by large-area suspended roof energy amplification in multifield environment.

(2) The visual information of potential multidisaster sources in Wudong coal mine is obtained by BTTEM. From the type of disaster, Wudong coal mine has hidden danger of roof safety and suspected water disasters.

(3) The roof above $2250-2600 \mathrm{~m}$ of the south roadway is relatively complete, and there are two low resistivity abnormal areas within the south roadway strike of 2320-2340 $\mathrm{m}$ and 2390-2400 m, which shows that these areas are suspected rich water, and the lowest vertical height is $+613.8-+615.5 \mathrm{~m}$. After the implementation of water exploration and drainage, it shows that the aquifer pressure is reduced and effectively released.

(4) The roof blasting holes are constructed in $+575 \mathrm{~m}$ south roadway, $+587 \mathrm{~m}$ measure roadway, and blasting chamber. MS-TEM monitoring shows that the apparent resistivity of the fractured area fluctuated obviously, the microseismic energy and events decreased significantly and maintained at a low level for two consecutive weeks, which confirmed that the release measures of deep high stress roof were effective. 


\section{Data Availability}

The test data used to support the findings of this study are included within the article. Readers can obtain data supporting the research results from the test data table in the article.

\section{Conflicts of Interest}

The authors declare that they have no conflicts of interest.

\section{Acknowledgments}

The authors would like to acknowledge the support of National Natural Science Foundation of China (nos. 51904227 and 51979218), the 973 Key National Basic Research Program of China (no. 2015CB251602), the Natural Science Foundation of Shaanxi Province (no. 2018JQ5194), the China Postdoctoral Science Foundation (no. 2017M623328XB), the Science and Technology Innovation Team Project of Shaanxi Province (no. 2018TD-038), project of the Youth Science Foundation of the National Natural Science Foundation of China (no. 52004201), and Joint Fund of National Natural Science Foundation of China (U1965107). The support from these agencies is gratefully acknowledged.

\section{References}

[1] H. P. Xie, L. X. Wu, and D. Z. Zheng, "Prediction on the energy consumption and coal demand of China in 2025," Journal of China Coal Society, vol. 44, pp. 1949-1960, 2019.

[2] P. G. Ranjith, J. Zhao, M. Ju, R. V. S. De Silva, T. D. Rathnaweera, and A. K. M. S. Bandara, "Opportunities and challenges in deep mining: a brief review," Engineering, vol. 3, no. 4, pp. 546-551, 2017.

[3] H. P. Xie, F. Gao, and Y. Ju, "Research and development of rock mechanics in deep ground engineering," Chinese Journal of Rock Mechanics and Engineering, vol. 34, no. 11, pp. 2161-2178, 2015.

[4] Q. H. Qian, "The characteristic scientific phenomena of engineering response to deep rock mass and the implication of deepness," Journal of East China Institute of Technology, vol. 27, no. 1, pp. 1-5, 2004.

[5] M. C. He, "Conception system and evaluation indexes for deep engineering," Yanshilixue Yu Gongcheng Xuebao/Chinese Journal of Rock Mechanics and Engineering, vol. 24, no. 16, pp. 2854-2858, 2005.

[6] M. C. He, H. P. Xie, S. P. Peng, and Y. D. Jiang, "Study on rock mechanics in deep mining engineering," Chinese Journal of Rock Mechanics and Engineering, vol. 24, no. 16, pp. 28032813, 2005.

[7] Z. Hongwei, X. Heping, and Z. Jianping, "Developments in researches on mechanical behaviors of rocks under the condition of high ground pressure in the depths," Advances in Mechanics, vol. 35, no. 1, pp. 91-99, 2005.

[8] L. Yuan, Y. D. Jiang, X. Q. He et al., "Research progress of precise risk accurate identification and monitoring early warning on typical dynamic disasters in coal mine," Journal of China Coal Society, vol. 43, no. 2, pp. 306-318, 2018.

[9] C. Zhou, Y. Chen, Q. Jiang, and W. Lu, "On generalized multifield coupling for fractured rock masses and its applications to rock engineering," Chinese Journal of Rock Mechanics and Engineering, vol. 27, no. 7, pp. 1329-1340, 2008.

[10] S. Bin, "On fields and their coupling in engineering geology," Journal of Engineering Geology, vol. 21, no. 5, pp. 673-680, 2013.

[11] F. Gong, J. Yan, X. Li, and S. Luo, "A peak-strength strain energy storage index for rock burst proneness of rock materials," International Journal of Rock Mechanics and Mining Sciences, vol. 117, pp. 76-89, 2019.

[12] Y. Jiang, Y. Zhao, H. Wang, and J. Zhu, "A review of mechanism and prevention technologies of coal bumps in China," Journal of Rock Mechanics and Geotechnical Engineering, vol. 9, no. 1, pp. 180-194, 2017.

[13] Z. Liu, R. Zhao, S. Dong, W. Wang, H. Sun, and D. Mao, "Scanning for water hazard threats with sequential water releasing tests in underground coal mines," Journal of $\mathrm{Hy}$ drology, vol. 590, p. 125350, 2020.

[14] J. H. Fu and Y. P. Cheng, "Situation of coal and gas outburst in China and control countermeasures," Journal of Mining \& Safety Engineering, vol. 3, 2007.

[15] Q. Liu, J. Chai, S. Chen, D. Zhang, Q. Yuan, and S. Wang, "Monitoring and correction of the stress in an anchor bolt based on pulse pre-pumped brillouin optical time domain analysis," Energy Science \& Engineering, vol. 8, no. 6, pp. 2011-2023, 2020.

[16] Y. Zhang, S. Cao, N. Zhang, and C. Zhao, "The application of short-wall block backfill mining to preserve surface water resources in northwest China," Journal of Cleaner Production, vol. 261, p. 121232, 2021.

[17] X. P. Lai, J. J. Dai, and C. Li, "Analysis on hazard characteristics of overburden structure in steeply inclined coal seam," Journal of China Coal Society, vol. 45, no. 1, pp. 122-130, 2020.

[18] X. Lai, P. Shan, J. Cao, H. Sun, Z. Suo, and F. Cui, "Hybrid assessment of pre-blasting weakening to horizontal section top coal caving (HSTCC) in steep and thick seams," International Journal of Mining Science and Technology, vol. 24, no. 1, pp. 31-37, 2014.

[19] L. Zhao, Statistical Thermophysics, Science Press, Beijing, China, 2019.

[20] Q. Liu, S. Chen, S. Wang, J. Chai, and D. Zhang, "Experimental development process of a new cement and gypsumcemented similar material considering the effect of moisture," Geofluids, vol. 2020, Article ID 8831801, 14 pages, 2020.

[21] C. Wang, X. Zou, Z. Han, Y. Wang, and J. Wang, "An automatic recognition and parameter extraction method for structural planes in borehole image," Journal of Applied Geophysics, vol. 135, pp. 135-143, 2016.

[22] Z. Guo, G. Xue, J. Liu, and X. Wu, "Electromagnetic methods for mineral exploration in China: a review," Ore Geology Reviews, vol. 118, p. 103357, 2020.

[23] J. Yu, Transient Electromagnetic Method for Mine Exploration, China University of Mining and Technology Press, Xuzhou, China, 2007. 